\title{
Flagellin gene PCR-RFLP analysis of a panel of strains from the Burkholderia cepacia complex
}

\author{
CRAIG WINSTANLEY, MARIA G. DETSIKA, KERRY J. GLENDINNING, YASMIN N. PARSONS and \\ C. ANTHONY HART \\ Department of Medical Microbiology and Genitourinary Medicine, University of Liverpool, Duncan Building, \\ Daulby Street, Liverpool L69 3GA
}

\begin{abstract}
Burkholderia cepacia, an important opportunist pathogen, is genetically heterogeneous. The $B$. cepacia complex has been subdivided into a number of genospecies or genomovars. A flagellin gene PCR-RFLP method was applied to a representative panel of strains of known genomovar. The technique was able to distinguish strains of $B$. multivorans from other members of the $B$. cepacia complex on the basis of amplicon size (typical of type I rather than type II flagellins) with the exception of one genomovar I strain. There was considerable variation in RFLP patterns amongst the panel of strains; only two pairs of strains were indistinguishable with both HaeIII and MspI digestion. Where RFLP patterns matched with both enzymes or a single enzyme, matching strains were always in the same genomovar. It was possible to distinguish the UK cystic fibrosis epidemic strain from all other members of the panel, including nine other genomovar III strains. The level of variation suggests that flagellin genotyping is a useful method for discriminating between $B$. cepacia strains.
\end{abstract}

\section{Introduction}

Burkholderia cepacia is an important opportunist pathogen associated with cystic fibrosis (CF) $[1,2]$, chronic granulomatous disease (CGD) [3] and septicaemia [4]. There is considerable genetic heterogeneity among $\mathrm{CF}$ and other isolates identified as $B$. cepacia and the $B$. cepacia complex has been subdivided into several genomic species or genomovars [5]. Although the majority of $\mathrm{CF}$ epidemic isolates, including the UK CF ET12 lineage, belong to the same genomovar (genomovar III), CF isolates belonging to most other genomovars have been isolated [6].

Previous studies reported that the majority of isolates of $B$. cepacia can be classified into two types on the basis of flagellin protein size [7] and demonstrated that the flagellin gene $(\mathrm{fliC})$ exhibited considerable heterogeneity in $B$. cepacia $[7,8]$. Variation between strains can be observed rapidly by PCR/RFLP analysis of $B$. cepacia $\mathrm{fliC}$ amplicons. However, in previous studies, genomovar designations were known for only a few of the strains studied. A panel of representative strains for

Received 3 Jan. 2001; revised version received 7 March 2001; accepted 19 March 2001.

Corresponding author: Dr C. Winstanley (e.mail: C.Winstanley @1iverpool.ac.uk). the B. cepacia complex has been proposed [6], including representatives of all major genomic species and genomovars. This study describes the application of the fliC PCR/RFLP typing method to the study of genetic variability amongst this panel of strains and assesses the correlation between flagellin genotype and genomovar designation.

\section{Materials and methods}

\section{B. cepacia strains}

Most of the bacterial strains used in this study were included in a panel of representative strains reported previously [6] and are listed in Table 1. The strains tested also included PC259, LMG 16232, FC441 and LMG 10929 (B. vietnamiensis). Isolates were maintained in the laboratory on nutrient agar.

\section{PCR/RFLP analysis of B. cepacia flagellin genes}

Flagellin gene oligonucleotide primers BC4 (CTGGTC GCACAGCAGAACCTGAAC; N-terminal) and BCR12 (ACAG/TGTTCGCGGTTTCCTG; C-terminal) [7] were obtained from Genosys (Cambridge). Cells taken from a nutrient agar plate were suspended in sterile distilled water $(20 \mu \mathrm{l})$ and boiled for $5 \mathrm{~min}$. This lysed suspension $(1 \mu \mathrm{l})$ was used directly in a standard 
Table 1. Matching fliC PCR-RFLP patterns amongst strains of the B. cepacia complex

\begin{tabular}{|c|c|c|c|}
\hline Strain no. & Same Hae III digest & Same $M s p$ I digest & Same digest with both enzymes \\
\hline \multicolumn{4}{|l|}{ Genomovar I } \\
\hline ATCC $25416^{\mathrm{T}}$ & - & ATCC17759, LMG17997 & - \\
\hline ATCC17759 & - & ATCC $25416^{\mathrm{T}}$ LMG 17997 & - \\
\hline CEP509 & - & - & - \\
\hline LMG 17997 & - & ATCC $25416^{\mathrm{T}}$ ATCC17759 & - \\
\hline \multicolumn{4}{|l|}{ B. multivorans } \\
\hline C5393 & - & - & - \\
\hline LMG $13010^{\mathrm{T}}$ & C1962 & CF-A1-1, C1962 & C1962 \\
\hline $\mathrm{C} 1576$ & - & - & - \\
\hline CF-A1-1 & - & C1962, LMG $13010^{\mathrm{T}}$ & - \\
\hline JTC & - & - & - \\
\hline C1962 & LMG $13010^{\mathrm{T}}$ & LMG $13010^{\mathrm{T}}$ CF-A1-1 & LMG $13010^{\mathrm{T}}$ \\
\hline ATCC 17616 & $249-2$ & $249-2$ & $249-2$ \\
\hline $249-2$ & ATCC 17616 & ATCC 17616 & ATCC 17616 \\
\hline \multicolumn{4}{|l|}{ Genomovar III* } \\
\hline $\mathrm{J} 2315$ (III-A) & $\mathrm{C} 6433, \mathrm{C} 5424, \mathrm{BC} 7, \mathrm{~K} 56-2$ & - & - \\
\hline BC7 (III-A) & J2315, C6433, C5424, K56-2 & - & - \\
\hline K56-2 (III-A) & $\mathrm{J} 2315, \mathrm{C} 6433, \mathrm{C} 5424, \mathrm{BC} 7$ & ATCC 17765, C5424 & C5424 \\
\hline C5424 (III-A) & $\mathrm{J} 2315, \mathrm{BC} 7, \mathrm{C} 6433, \mathrm{~K} 56-2$ & K56-2, АТCC 17765 & K56-2 \\
\hline C6433 (III-A) & $\mathrm{J} 2315, \mathrm{C} 5424, \mathrm{BC} 7, \mathrm{~K} 56-2$ & - & - \\
\hline C1394 (III-B) & - & - & - \\
\hline PC184 (III-B) & - & - & - \\
\hline CEP511 (III-B) & - & - & - \\
\hline $\mathrm{J} 415$ & - & - & - \\
\hline ATCC 17765 (III-B) & - & K56-2, C5424 & - \\
\hline \multicolumn{4}{|l|}{ B. stabilis } \\
\hline LMG 14294 & - & C7322 & - \\
\hline C7322 & - & LMG 14294 & - \\
\hline LMG 14086 & - & - & - \\
\hline LMG 18888 & - & - & - \\
\hline
\end{tabular}

*Where known the designation of a strain following subdivision of genomovar III into two groups on the basis of recA sequence is indicated [11]

amplification mixture. Amplifications were done in 50- $\mu 1$ volumes containing Taq DNA polymerase (Helena Biosciences, Sunderland, Tyne and Wear) 2.5 units, $1 \times$ TaqMaster (Helena Biosciences), $200 \mathrm{nM}$ of each primer (BC4 and BCR12), $1 \times$ Taq buffer, $2.5 \mathrm{~mm}$ $\mathrm{MgCl}_{2}$ and $100 \mu \mathrm{M}$ nucleotides (dATP, dCTP, dGTP, dTTP) for 30 cycles consisting of $95^{\circ} \mathrm{C}(1 \mathrm{~min}), 60^{\circ} \mathrm{C}$ $(1 \mathrm{~min})$ and $72^{\circ} \mathrm{C}(2 \mathrm{~min})$.

Amplified product samples $(5 \mu \mathrm{l})$ were digested with the restriction endonucleases Hae III and Msp I using the conditions recommended by the supplier (Helena Biosciences). These digests were then subjected to electrophoresis on MetaPhor agarose $2 \% \mathrm{w} / \mathrm{v}$ gels (Flowgen) alongside pUC19/Msp I (Helena Biosciences) or Novagen PCR markers (CN Biosciences, Nottingham).

\section{Results}

Flagellin gene amplicons were obtained from 26 of the 30 strains tested. All four strains that failed to yield an amplified product were from the same genospecies $(B$. vietnamiensis, formerly genomovar $\mathrm{V}$ ). Of the remaining 26 strains, nine yielded larger amplified products indicative of type I flagellins $(1.4 \mathrm{~kb}$ compared with $1.0 \mathrm{~kb}$ for type II flagellins). Eight of these strains were

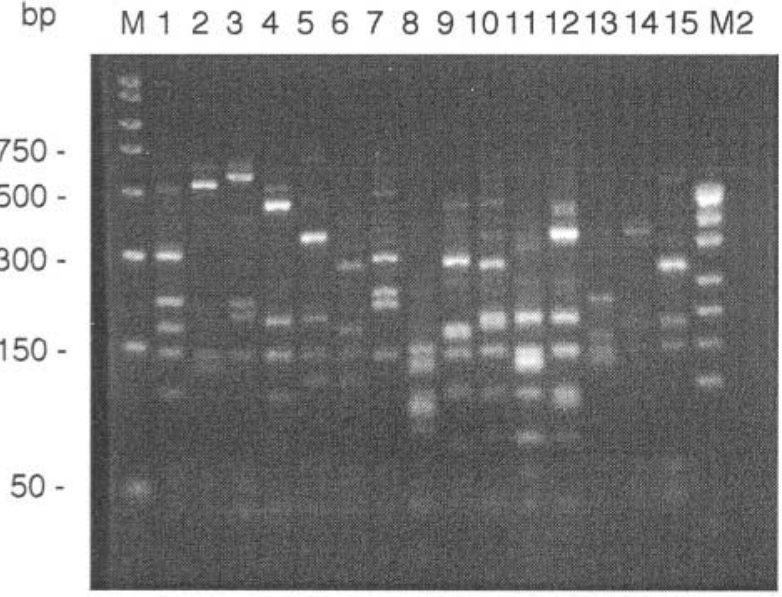

Fig. 1. $f i C$ PCR-RFLP patterns generated with the endonuclease HaeIII. The gel includes all the HaeIII patterns generated from strains in this study: lane 1, ATCC 17759; 2, C6433; 3, ATCC 17616; 4, C1962; 5, JTC; 6, J415; 7, ATCC 25416; 8, CEP509; 9, LMG 17997; 10, C5393; 11, C1576; 12, CF-A1-1; 13, PC184; 14, CEP511; 15, ATCC17765; $M$ and M2, PCR markers and pUC19/Msp I respectively.

from the same genospecies (B. multivorans, formerly genomovar II).

PCR/RFLP analysis of $f i c$ amplicons indicated extensive variation amongst the panel of strains (Fig. 
1). Of the 26 strains yielding amplicons, only six matched the RFLP patterns of another strain for both Hae III and Msp I. Nine strains matched at least one other strain's Hae III pattern whilst differing in the $M s p$ I pattern and 13 strains matched at least one other strain's MspI pattern whilst differing in the Hae III pattern (Table 1). RFLP patterns were compared with those obtained in previous studies [7,8]. Only three of the strains used in this study matched with an RFLP group reported in previous studies. Strain ATCC 17759 was included in a previous study (under the designation NCIB 9085) and is in flagellin gene RFLP group IX [7]. Strain J2315, representative of the UK CF epidemic strain, was also included in previous studies (under the designation E241) and is in RFLP group I $[7,8]$. The only genuine match between different isolates was between strain C6433 and the RFLP group 'Senegal', identified from strains isolated in a paediatric ward in Senegal [8].

\section{Discussion}

PCR amplification of the $f i c$ gene with the primers used in this study led to discrimination between genospecies failing to yield a product (B. vietnamiensis), genospecies that yielded a type I flagellin gene product (B. multivorans and one genomovar I strain) and the remainder, that yielded type II flagellin gene products. In previous studies the one known strain of B. multivorans (genomovar II) also gave an amplicon indicative of a type I flagellin $(1.4 \mathrm{~kb})[7,8]$. One strain reported as genomovar I also yielded an amplicon typical of type I flagellins. As only one of the four genomovar I isolates used in this study yielded a type I flagellin gene product, it is apparent that strains from this genomovar can produce either type I or type II flagellin. The failure to obtain $f i C$ amplicons from $B$. vietnamiensis is probably due to the inability of one or both of the primers to bind to the $f i c$ genes in this genospecies, and suggests that $B$. vietnamiensis $f i C$ genes are less related to the $\mathrm{fliC}$ genes of other members of the B. cepacia complex than such genes are to each other. It may be possible to rectify this problem with different primers. However, the variable nature of the $\mathrm{fliC}$ gene makes it difficult to design primers that are effective for all members of the $B$. cepacia complex.

Earlier studies reported that $f i C$ PCR-RFLP analysis may be a useful epidemiological tool for identification of $\mathrm{CF}$ epidemic strains and for discrimination between these and other strains $[7,8]$. The present study has demonstrated that $\mathrm{fliC}$ genotyping can be used to distinguish strain J2315 (genomovar III, ET12 lineage) from other strains of the genomovar III genospecies, including three containing the BCESM marker [9] and cblA [10], both indicative of epidemic strains. Although strain $\mathrm{J} 2315 \mathrm{fliC}$ amplicons could be distinguished from those of other genomovar III strains with the endonuclease Msp I, Hae III digestion yielded patterns that were indistinguishable from four other genomovar III strains. These five strains belong to the same subdivision of genomovar III (III-A) based on recA sequences [11] and four have been attributed to the same RAPD and PFGE strain types [6]. Two of these genomovar III strains (K56-2 and C5424) were indistinguishable from each other when digested with either restriction endonuclease. Interestingly, these two strains are both Canadian CF epidemic isolates [6]. The only other strains indistinguishable with either of the two endonucleases were members of the $B$. multivorans genospecies. Strain 249-2 is a derivative of ATCC 17616 [12] which has part of its genome deleted. Therefore, it is not surprising that these two strains are indistinguishable by flagellin genotyping. The apparently unrelated strains C1962 (a UK clinical isolate) and LMG 13010 (a CF isolate from Belgium) were indistinguishable with either enzyme. A number of other strains from the panel shared identical $f l i C$ RFLP patterns with $M s p$ I. In each case, strains sharing RFLP patterns were located in the same genospecies. In this respect, typing by $f l i C$ RFLPs is consistent with genomovar designation.

The most notable observation in this study is the remarkable degree of variation in $\mathrm{fliC}$ genes of the $B$. cepacia complex. There were very few matches between the $f l i C$ PCR-RFLP patterns of strains used in this study and those of strains analysed previously. Although flagellin genes do often exhibit variation [13], the level of $f l i C$ variation in the B. cepacia complex is higher than in many other bacterial pathogens, such as the important CF pathogen Pseudomonas aeruginosa [14, 15]. In a study of $f l i C$ PCR-RFLP analysis of P. aeruginosa isolates, although six restriction endonucleases were used, strain discrimination was much lower than in B. cepacia [14]. This suggests that flagellin genotyping is a highly discriminatory method in B. cepacia and can be used as an epidemiological tool for the identification of the same strain from different sources.

C.W. and C.A.H. acknowledge the support of the UK Cystic Fibrosis Trust (grant reference PJ486). The authors also thank John Govan (Department of Medical Microbiology, University Medical School, Edinburgh) and Eshwar Mahenthiralingam (Cardiff School of Biosciences, Cardiff University) for providing strains.

\section{References}

1. Govan JRW, Hughes JE, Vandamme P. Burkholderia cepacia: medical, taxonomic and ecological issues. J Med Microbiol 1996; 45: 395-407.

2. Govan JR, Deretic V. Microbial pathogenesis in cystic fibrosis: mucoid Pseudomonas aeruginosa and Burkholderia cepacia. Microbiol Rev 1996; 60: 539-574.

3. Speert DP, Bond M, Woodman RC, Curnutte JT. Infection with Pseudomonas cepacia in chronic granulomatous disease: role of nonoxidative killing by neutrophils in host defense. J Infect Dis 1994; 170: 1524-1531.

4. van Laer F, Raes D, Vandamme $\mathrm{P}$ et al. An outbreak of Burkholderia cepacia with septicemia on a cardiology ward. 
Infect Control Hosp Epidemiol 1998; 19: 112-113.

5. Vandamme P, Holmes B, Vancanneyt $\mathrm{M}$ et al. Occurrence of multiple genomovars of Burkholderia cepacia in cystic fibrosis patients and proposal of Burkholderia multivorans sp. nov. Int $J$ Syst Bacteriol 1997; 47: 1188-1200.

6. Mahenthiralingam E, Coenye T, Chung JW et al. Diagnostically and experimentally useful panel of strains from the Burkholderia cepacia complex. J Clin Microbiol 2000; 38: 910-913.

7. Hales BA, Morgan JAW, Hart CA, Winstanley C. Variation in flagellin genes and proteins of Burkholderia cepacia. J Bacteriol 1998; 180: 1110-1118.

8. Winstanley C, Hales BA, Morgan JAW et al. Analysis of fliC variation among clinical isolates of Burkholderia cepacia. $J$ Med Microbiol 1999; 48: 657-662.

9. Mahenthiralingam E, Simpson DA, Speert DP. Identification and characterization of a novel DNA marker associated with epidemic Burkholderia cepacia strains recovered from patients with cystic fibrosis. J Clin Microbiol 1997; 35: 808-816.

10. Sajjan US, Sun L, Goldstein R, Forstner JF. Cable $(c b l)$ type II pili of cystic fibrosis-associated Burkholderia (Pseudomonas) cepacia: nucleotide sequence of the cblA major subunit pilin gene and novel morphology of the assembled appendage fibers. J Bacteriol 1995; 177: 1030-1038.

11. Mahenthiralingam E, Bischof J, Byrne SK et al. DNA-based diagnostic approaches for identification of Burkholderia cepacia complex, Burkholderia vietnamiensis, Burkholderia multivorans, Burkholderia stabilis, and Burkholderia cepacia genomovars I and III. J Clin Microbiol 2000; 38: 3165-3173.

12. Cheng H-P, Lessie TG. Multiple replicons constituting the genome of Pseudomonas cepacia 17616. J Bacteriol 1994; 176: 4034-4042.

13. Winstanley C, Morgan JAW. The bacterial flagellin gene as a biomarker for detection, population genetics and epidemiological analysis. Microbiology 1997; 143: 3071-3084.

14. Winstanley C, Coulson MA, Wepner B, Morgan JAW, Hart CA. Flagellin gene and protein variation amongst clinical isolates of Pseudomonas aeruginosa. Microbiology 1996; 142: 2145-2151.

15. Morgan JAW, Bellingham NF, Winstanley C, Ousley MA, Hart CA, Saunders JR. Comparison of flagellin genes from clinical and environmental Pseudomonas aeruginosa isolates. Appl Environ Microbiol 1999; 65: 1175-1179. 